\title{
Studies of $\mathrm{BF}_{3}$ Complex Catalysts in the Alkylation Reaction of Benzene Homologues
}

\section{Part 3. Life of $\mathrm{BF}_{3}-\mathrm{H}_{2} \mathrm{O}$ Complex Catalyst in Alkylation Reactions*}

\author{
by Norihiko Yoneda**, Eiji Hasegawa**, Kazuo Aomura** and Hiroshi Ohtsuka**
}

\begin{abstract}
Summary: The life of $\mathrm{BF}_{3}-\mathrm{H}_{2} \mathrm{O}$ complex catalyst in the alkylation reaction of benzene homologues with propylene was studied and the catalytic behaviors of $\mathrm{BF}_{3}-\mathrm{H}_{2} \mathrm{O}$ complex in the polymerization of propylene were also observed.

From the experimental results obtained, the following conclusions may be drawn.

1) In the propylation of aromatic hydrocarbons with $B F_{3}-H_{2} \mathrm{O}$ complex catalyst, the main at-

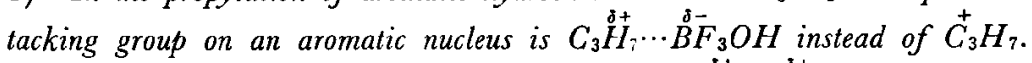

2) The attacking group being a polarized complex, $\mathrm{C}_{3} \mathrm{\delta H}_{7} \cdots \stackrel{\dot{\delta}+}{B F_{3}} \mathrm{OH}$, the inductive effect of the alkyl group on the aromatic mucleus on it is not so influential as in the case of the attack by carbonium ions.
\end{abstract}

3) Hence, in this case, the steric or probability factor has the priority over the inductive effect in the propylation of aromatic hydrocarbons. This is the reason why benzene is the most reactive and has the strongest catalyst regenerationg ability as compared with alkylbenzene in the propylation reaction with $\mathrm{BF}_{3}-\mathrm{H}_{2} \mathrm{O}$ complex catalyst.

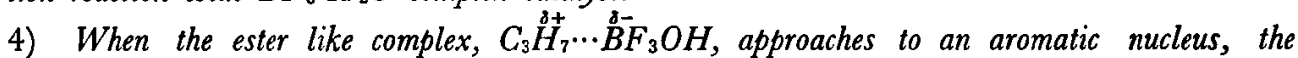
exchange of $\mathrm{C}_{3}^{++} H_{7}$ in the complex for a proton on the aromatic nucleus occurs to produce alkylated aromatic hydrocarbons and regenerated catalyst $\mathrm{HBF}_{3} \mathrm{OH}$. And this exchange reaction can be accomplished only when the complex approaches very closely to the nucleus.

5) The attack of the ester like complex to the aromatic nucleus is accelerated by the presence of a large amount of the $\mathrm{BF}_{3}-\mathrm{H}_{2} \mathrm{O}$ complex catalyst of high $\mathrm{BF}_{3}$ concentration. Hence, the increase of the catalyst amount favors the elongation of the catalyst life.

6) In the polymerization of propylene with $\mathrm{BF}_{3}-\mathrm{H}_{2} \mathrm{O}$ complex catalyst, the deterioration of the catalyst (the accumulation of the ester like complex, $C_{3} H_{7}^{b+} \cdots B F_{3} O H$ ) is more rapid than in the case of the propylation of benzene homologues. And the molar ratio of $\mathrm{C}_{3} \mathrm{H}_{6} / \mathrm{HBF}_{3} \mathrm{OH}$ in the ester like complex is found to be $1: 1$.

\section{Introduction}

The activity of the $\mathrm{BF}_{3}-\mathrm{H}_{2} \mathrm{O}$ complex catalyts in the alkylation reaction of benzene with propylene is very high and almost constant in the initial stage of the reaction, however, after some time it drops very rapidly.

In part $1^{1)}$, the authors found that the activity drop was caused by the chemisorption of feed propylene to the catalyst to form an ester like substance, $\mathrm{C}_{3} \stackrel{\delta+}{\mathrm{H}} \cdots \stackrel{8+}{\mathrm{B} F_{3} \mathrm{OH}}$. However, this substance was not so stable as the sulfuric acid ester. ${ }^{2), 3)}$ It was decomposed into propylene polymer and the regenerated active catalyst by heating, or it reacted with benzene homologues to produce alkylated aromatics and the regenerated

* Received November 22, 1968.

** Chemical Engineering Department, Hokkaido University (Sapporo, Japan). catalyst. In both cases, the reaction is accelerated by the addition of fresh $\mathrm{BF}_{3}-\mathrm{H}_{2} \mathrm{O}$ catalyst of high $\mathrm{BF}_{3}$ concentration.

Hence, in the reaction medium of the propylation of benzenc homologues with propylenc, both the accumulation of the ester like substance which causes the catalyst deterioration, and the decomposition of this substance, causting the catalyst regeneration, occur in parallel. And it may be said that the competition between these reactions determines the life of the $\mathrm{BF}_{3}-\mathrm{H}_{2} \mathrm{O}$ complex catalyst.

In this paper, the effects of the amount of the catalyst, $\mathrm{BF}_{3}$ concentration in the catalyst and the species of aromatic hydrocarbons on the life of the catalyst (expressed as the total amount of absorbed propylene until the deterioration of catalyst takes place) in the propylation reaction 
of aromatic hydrocarbons with propylene are described. The catalytic behaviors of $\mathrm{BF}_{3}-\mathrm{H}_{2} \mathrm{O}$ complex catalyst in the polymerization of propylene are also studied.

\section{Apparatus and Procedure}

A four-necked flask of $500 \mathrm{cc}$ capacity was used as a reaction vessel for the alkylation and polymerization experiments. Propylene was conducted into the flask containing the catalyst and aromatic hydrocarbons or containing the catalyst and solvent under stirring. The reaction vessel and its accessories were shown in the previous paper'1.

In some experiments, a continuous rcaction apparatus with catalyst and product removers was used as shown in Fig. 1.

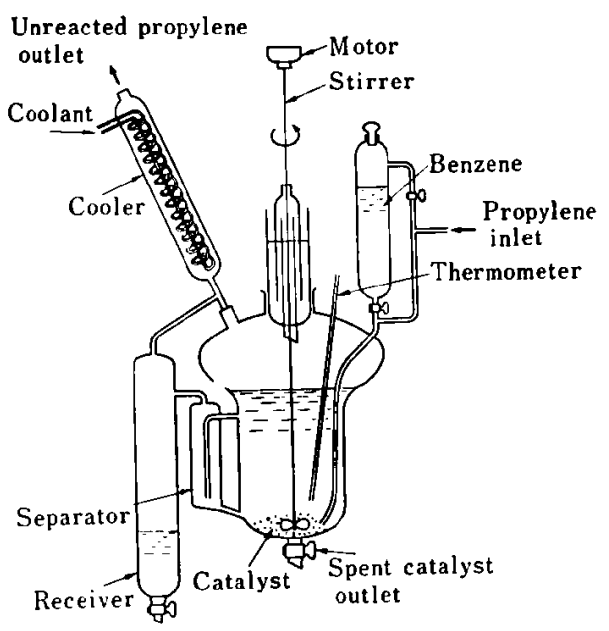

Fig. 1 Continuous Reaction Vessel

\section{Experimental Results}

\subsection{The Effects of the Amount of Catalyst and Its $\mathrm{BF}_{3}$ Concentration on the Life of $\mathrm{BF}_{3}-\mathrm{H}_{2} \mathrm{O}$ Complex Catalyst}

Benzene was alkylated with propylene at $10^{\circ} \mathrm{C}$ in the presence of $\mathrm{BF}_{3}-\mathrm{H}_{2} \mathrm{O}$ complex catalyst. Each experiment was continued until no more propylene was absorbed. Total amount of absorbed propylene is plotted against the amount of catalyst in Fig. 2. The results are shown by different curves according to different $\mathrm{BF}_{3}$ concentrations in the catalyst.

In Fig. 2, the amount of the alkylate (cumene) is also shown by broken line.

In the case of the $\mathrm{BF}_{3}-\mathrm{H}_{2} \mathrm{O}$ complex catalyst having $\mathrm{BF}_{3} / \mathrm{H}_{2} \mathrm{O}$ molar ratio of 0.97 , the total amount of the reacted propylene increased very

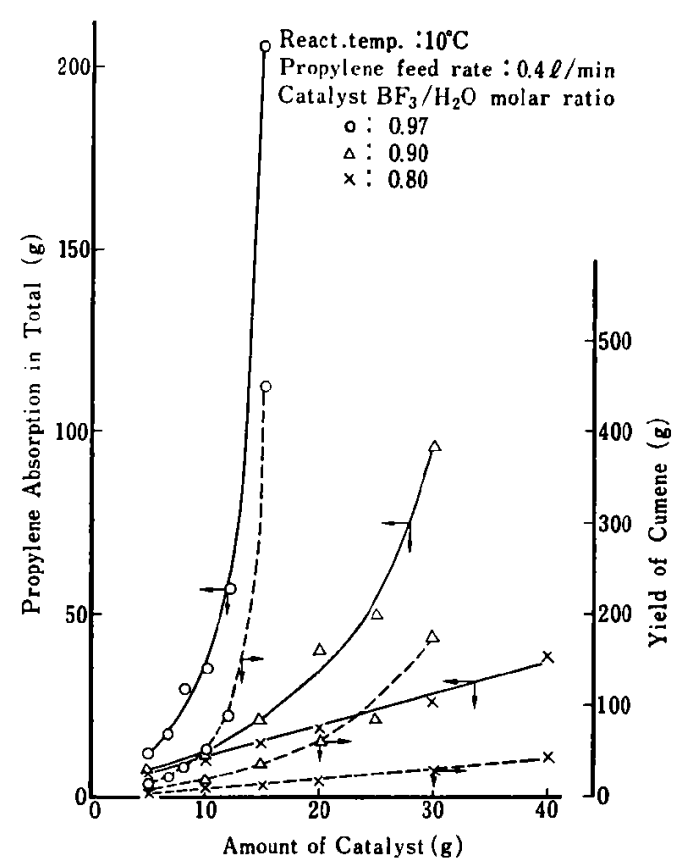

Fig. 2 Relationship between the Amount of the Catalyst and Total Propylene Absorption Together with Yield of Cumene in the Propylation of Benzene

rapidly with the increase of the catalyst amount. However, in the case of the catalyst having lower $\mathrm{BF}_{3}$ concentration, the increasing tendency of the total amount of absorbed propylene with the increase of the catalyst amount was not so remarkable as in the case of $0.97 \mathrm{BF}_{3} / \mathrm{H}_{2} \mathrm{O}$ molar ratio catalyst. Especially, at the molar ratio of $\mathrm{BF}_{3} /$ $\mathrm{H}_{2} \mathrm{O} 0.80$, the total amount of absorbed propylene increased very gradually with the increase of the catalyst amount showing a good straight line.

3.2 The Life of $\mathrm{BF}_{3}-\mathrm{H}_{2} \mathrm{O}$ Complex Catalyst in the Propylation Reaction of Aromatic Hydrocarbons

The life of $\mathrm{BF}_{3}-\mathrm{H}_{2} \mathrm{O}$ complex catalyst in the propylation reaction of aromatic hydrocarbons was observed at the reaction tempcrature of $10^{\circ} \mathrm{C}$. The results are shown in Fig. 3 .

The life of the catalyst (expressed as the total amount of absorbed propylene) in the propylation reaction varied according to the species of aromatic hydrocarbons in the following order:

benzene $\gg$ toluene $>$ ethylbenzene $>$ isopropylbenzene.

The relation between the catalyst amount and the total amount of absorbed propylene in the propylation reaction of each of aromatic hydrocarbons is shown in Fig. 4.

As shown in Fig. 4, in the case of the propyla- 


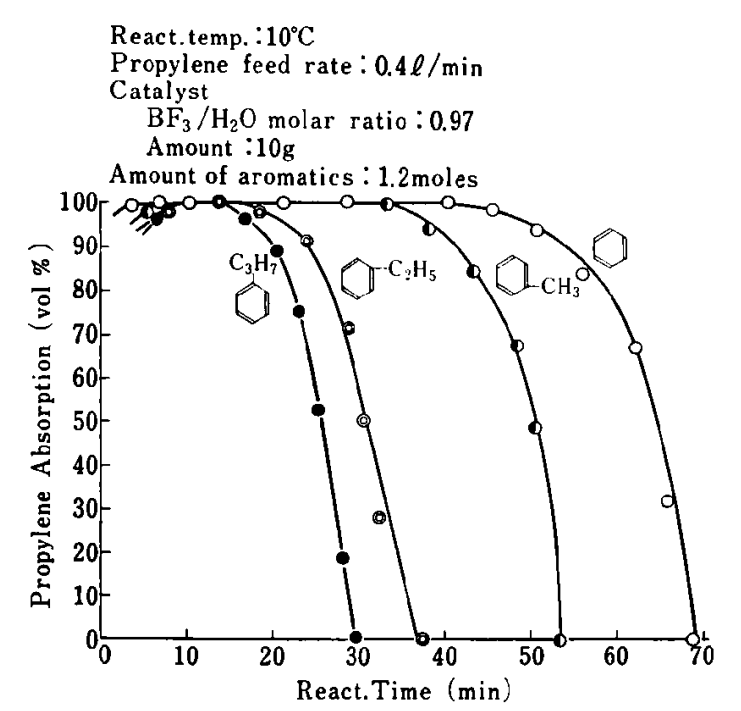

Fig. 3 Life of $\mathrm{BF}_{3}-\mathrm{H}_{2} \mathrm{O}$ Complex Catalyst in the Propylation Reaction of Aromatic Hydrocarbons

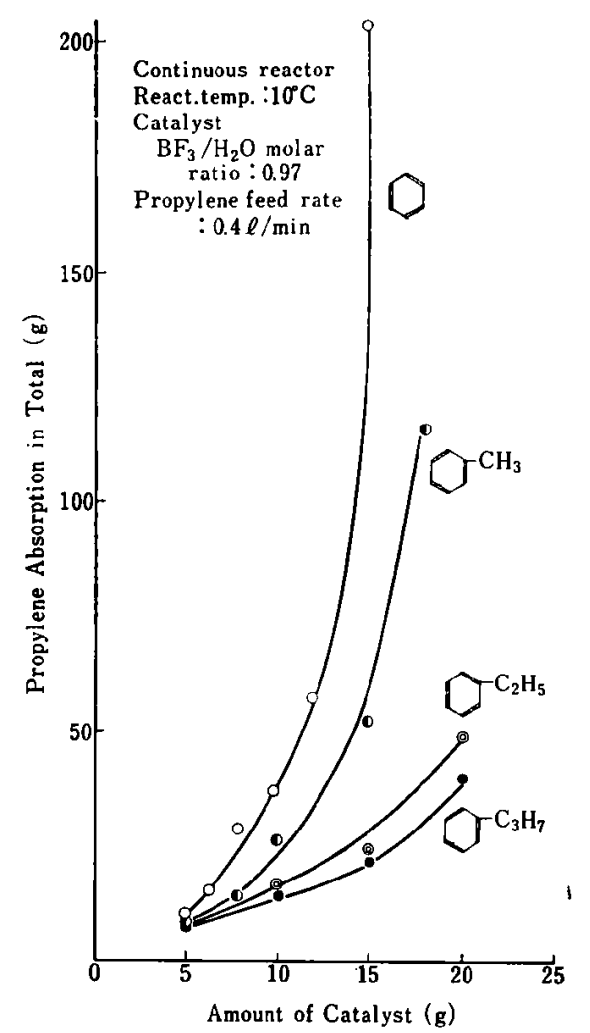

Fig. 4 Relationship between the Amount of Catalyst and Total Propylene Absorption in the Propylation of Aromatics

tion of benzene, the total amount of absorbed propylene increased very rapidly with the increase of the catalyst amount. This tendency was not so remarkable as in the alkylation of toluene, ethylbenzene or isopropylbenzene. And the increasing rate of the total amount of absorbed propylene with the increase of the catalyst amount decreased in the following order: benzene $\gg$ toluene $>$ ethylbenzene $>$ isopropylbenzene.

\subsection{Life of $\mathrm{BF}_{3}-\mathrm{H}_{2} \mathrm{O}$ Complex Catalyst in the Polymerization of Propylene}

The polymerization of propylene in the presence of $\mathrm{BF}_{3}-\mathrm{H}_{2} \mathrm{O}$ complex catalyst was made in order to investigate the deterioration of the catalyst in the course of the reaction. Cyclohexane was used as solvent. The results are shown in Fig. 5.

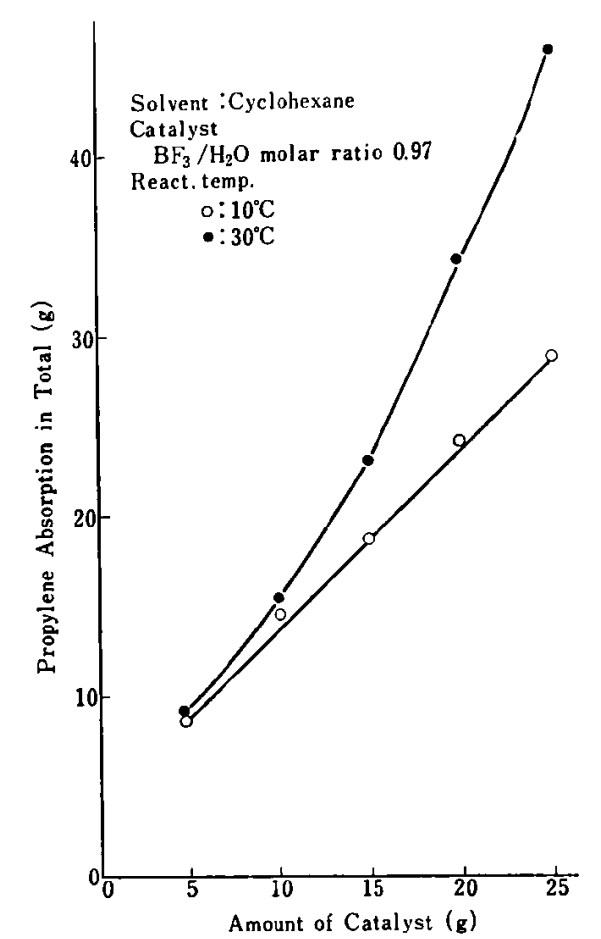

Fig. 5 Polymerization of Propylene with $\mathrm{BF}_{3}-\mathrm{H}_{2} \mathrm{O}$ Complex Catalyst

The deterioration of the catalyst took place more rapidly in the polymerization of propylene than in the propylation of benzene homologues.

The deterioration rate of the catalyst was faster at the reaction temperature of $10^{\circ} \mathrm{C}$ than that at $30^{\circ} \mathrm{C}$. At $10^{\circ} \mathrm{C}$, a linear relation was observed between the catalyst amount and the total amount of absorbed propylene, whereas, at $30^{\circ} \mathrm{C}$, the total amount of absorbed propylene showed some logarithmic increase with the increase of the catalyst amount.

According to the fractional distillation test and the infrared spectroscopic determination, the propylene polymer thus obtained was found to consist mainly of tetramers and pentamers of propylene.

The spent catalyst was a milky liquid. On standing it for 1 2 days, oil separated out on on the catalyst surface. It was accelerated by adding the fresh catalyst under stirring. This 
oil was the mixture of propylene polymers larger than pentamers. This polymer oil was considered to be produced from the propylene chemisorbed to the catalyst by the following reaction.

$$
\left.n\left(\underset{\mathrm{CH}_{3}}{\mathrm{CH}_{3}}\right\rangle^{\delta} \mathrm{C} \cdot \mathrm{H} \cdots \stackrel{\delta}{\mathrm{B}} \mathrm{F}_{3} \mathrm{OH}\right) \rightarrow\left(\mathrm{C}_{3} \mathrm{H}_{6}\right)_{n}+n \mathrm{HBF} \mathrm{OH}
$$

After the oil separation, the spent catalyst almost recovered its catalytic activity. By measuring the amount of the spent eatalyst, it was found that the molar ratio of the chemisorbed propylene to the amount of $\mathrm{BF}_{3}$ in the catalyst was about 1.0 .

On the other hand, if a large amount of water was added to the spent catalyst, isopropyl alcohol and isopropyl ether were found to be produced in the water solution together with a negligible amount of oil. These oxygenated compounds were considered to be produced by the hydrolysis of the propylene-catalyst complex, $\stackrel{\mathrm{C}}{3}_{3}^{+} \mathrm{H}_{7} \cdots \dot{\mathrm{BF}}_{3} \mathrm{OH}$.

\section{Discussion}

As described in the previous paper ${ }^{13}$, the active form of the $\mathrm{BF}_{3}-\mathrm{H}_{2} \mathrm{O}$ complex catalyst is $\mathrm{HBF}_{3} \mathrm{OH}$. $\mathrm{HBF}_{3} \mathrm{OH}$ is a strong Brönsted acid and reacts with propylene in two ways. It converts propylene into isopropyl carbonium ion by proton transfer (Route (1) in Fig. 6), or it combines with propylene to form an ester like complex (Route (2) in Fig. 6).

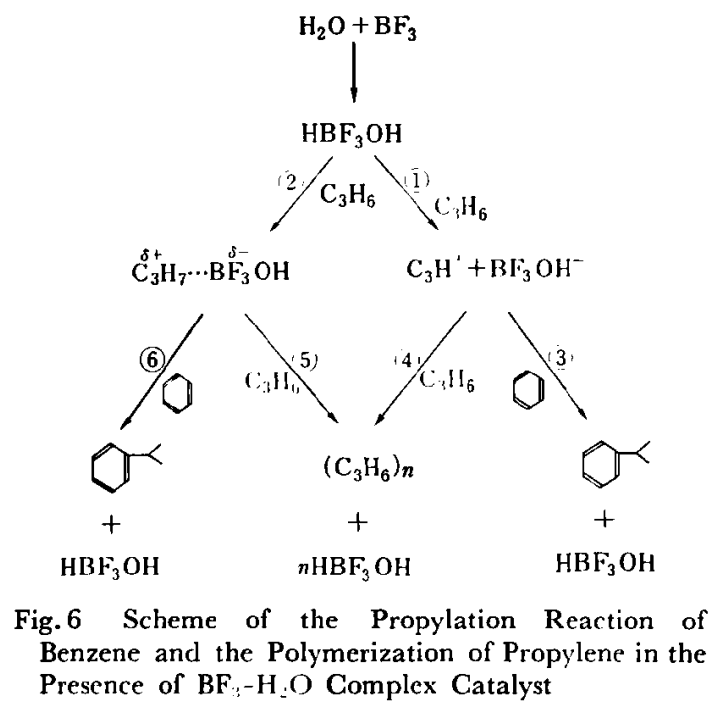

The ester like structure may be demonstrated by the fact that isopropyl alcohol and diisopropyl ether are obtained by hydrolyzing this complex.

$$
\begin{aligned}
& \underset{\mathrm{CH}_{3}}{\mathrm{CH}_{3}}>\stackrel{3}{\mathrm{C}} \cdot \overrightarrow{\mathrm{H}} \cdots \stackrel{8-}{\mathrm{B} F_{3} \mathrm{OH}}+\mathrm{H}_{2} \mathrm{O} \rightarrow \\
& \underset{\mathrm{CH}_{3}}{\mathrm{CH}_{3}}>\mathrm{CHOH}+\mathrm{HBF}_{3} \mathrm{OH}
\end{aligned}
$$

$2 \underset{\mathrm{CH}_{3}}{\mathrm{CH}_{3}}>\mathrm{CHOH}+\mathrm{HBF}_{3} \mathrm{OH} \rightarrow$
$\quad \mathrm{CH}_{3}>\mathrm{CH} \cdot \mathrm{O} \cdot \mathrm{CH}\left\langle\left\langle\mathrm{CH}_{3} \mathrm{CH}_{3}+\mathrm{BF}_{3} \cdot 2 \mathrm{H}_{2} \mathrm{O}\right.\right.$

If the propylation of benzene homologues or the polymerization of propylene in the presence of $\mathrm{HBF}_{3} \mathrm{OH}$ is assumed to proceed exclusively by Route (3) or Route (4) via Route (1) in Fig. 6 respectively, the deterioration of the catalyst would never happen. Actually, it is not the case.

On the other hand, there arc cxperimental evidences that an appreciable amount of propylene combines with $\mathrm{HBF}_{3} \mathrm{OH}$ to form such ester like complex as mentioned above. This ester like complex tends to decompose to the mixture of heavy propylene polymers and $\mathrm{HBF}_{3} \mathrm{OH}$ on long standing, by heating, or by the addition of fresh $\mathrm{HBF}_{3} \mathrm{OH}$.

This decomposition means the regeneration ot the catalyst. It is also found that the addition of benzene homologues to the ester like complex favors its decomposition and, in this case, propylated aromatics and $\mathrm{HBF}_{3} \mathrm{OH}$ are produced.

Based on the experimental results of the competitive propylation of benzene homologues with various $\mathrm{BF}_{3}$ complex catalysts as shown in Part $2^{4)}$, the authors considered that in the case of the $\mathrm{BF}_{3}-\mathrm{H}_{2} \mathrm{O}$ complex catalyst, the main attacking group to the aromatic nucleus in the propylation of benzene homologues is not an isopropyl carbonium ion but the ester like complex (Route (6) in Fig. 6). Naturally, the ester like complex must be reactive enough to interact with the aromatic nucleus under the reaction conditions. By this interaction between the aromatic nucleus and the ester like complex, propylated benzenes are produced and $\mathrm{HBF}_{3} \mathrm{OH}$ is regenerated at the same time. In other words, the ester like complex is decomposed by the reaction with aromatics and regenerates $\mathrm{HBF}_{3} \mathrm{OH}$. The velocity of this reaction seems to be slower than that of the formation of the ester like complex under usual reaction conditions. Hence, the accumulation of the ester like complex in the reaction medium occurs. This causes the apparent catalyst deterioration. The ester like complex is fairly stable at low temperatures (around $10^{\circ} \mathrm{G}$ ) or in the dilute catalyst $\left(\mathrm{BF}_{3} / \mathrm{H}_{2} \mathrm{O}\right.$ molar ratio $\leqq$ 0.8 ). Under these conditions, the reaction of benzene with this ester like complex, which means the regeneration of the catalyst, hardly occurs. Hence, the behaviors of the dilute $\mathrm{BF}_{3}-\mathrm{H}_{2} \mathrm{O}$ catalyst are very similar to those of 
sulfuric acid catalyst in the alkylation or in the polymerization reaction at low temperatures. That is, in the propylation of benzene with the dilute $\mathrm{BF}_{3}-\mathrm{H}_{2} \mathrm{O}$ catalyst at $10 \mathrm{C}_{3}$, almost straight line relation is obtained between the catalyst amount and the total amount of absorbed propylene as shown in Fig. 2.

However, as mentioned above, the ester like complex becomes unstable and mostly decomposes by reacting with aromatics in the presence of a large amount of $\mathrm{HBF}_{3} \mathrm{OH}$. Hence, when introducing propylene into the concentrated $\mathrm{BF}_{3}$ $\mathrm{H}_{2} \mathrm{O}$ complex catalyst $\left(\mathrm{BF}_{3} / \mathrm{H}_{2} \mathrm{O}\right.$ molar ratio $\geqq$ 0.9 ), the rate of accumulation of the ester like complex in the catalyst is very slow. Consequently, the catalyst has a long life. In this case, formation and decomposition of the ester like complex seem to proceed competitively.

As reported in the previous paper, ${ }^{4}$ the order of the reactivity of benzene homologues in the competitive propylation reaction in the presence of $\mathrm{BF}_{3}-\mathrm{H}_{2} \mathrm{O}$ complex catalyst was as following: benzene $>$ toluene $>$ ethylbenzene $>$ isopropyl-

benzene. This order coincides with the order of the length of the catalyst life in the propylation of each aromatic hydrocarbon with $\mathrm{BF}_{3}-\mathrm{H}_{2} \mathrm{O}$ complex catalyst as shown in Figs. 3 and 4 .

In the alkylation of benzene homologues, the substance attacking the benzene ring directly may be in the form of a carbonium ion $\left(R^{+}\right)$, an ion-pair $\left(\mathrm{R}^{+} \ldots \mathrm{Cat}^{-}\right)$or a polarized inter-

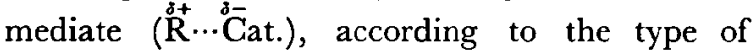
the alkylating reagents and the nature of the catalysts.

The form of the attacking substance exerts a great influence on the relative reactivity of benzene homologues.

In the case of the attack by a carbonium ion, the inductive effect of the alkyl groups on the benzene ring must be predominant. Hence, in this case, toluene and alkylbenzenes are more reactive than benzene in the alkylation reaction. The tertiary butylation of benzene homologues with $\mathrm{BF}_{3}-\mathrm{H}_{2} \mathrm{O}$ catalyst, ${ }^{\text {) }}$ or the tertiary butylation and the propylation of benzene homologues with $\mathrm{AlCl}_{3}-\mathrm{CH}_{3} \mathrm{NO}_{2}$ catalyst ${ }^{5}$ or with $\mathrm{BF}_{3}$ $n \mathrm{C}_{4} \mathrm{H}_{9} \mathrm{OH}$ catalyst ${ }^{1)}$ are such cases.

In the case of the attack by an ion-pair, or a polarized intermediate having a less positive charge than a carbonium ion, the inductive effect is surpassed by the stereochemical and probability effects. Hence, benzene showed a higher reactivity than toluene and other alkyl benzenes in the profylation with the catalysts such as $\mathrm{BF}_{3}-\mathrm{H}_{2} \mathrm{O}, \mathrm{BF}_{3}-\mathrm{H}_{3} \mathrm{PO}_{4}$ etc.

This is also the reason why benzene has the strongest decomposing ability for the ester like complex as compared with alkylbenzenes in the propylation reaction with $\mathrm{BF}_{3}-\mathrm{H}_{2} \mathrm{O}$ complex catalyst.

From the above discussions, the following conclusions may be drawn:

1) In the propylation of aromatic hydrocarbons with $\mathrm{BF}:-\mathrm{H}_{2} \mathrm{O}$ complex catalyst, the main attacking group on an aromatic nucleus is $\mathrm{C}_{3} \stackrel{\dot{s}}{\mathrm{H}_{7}} \ldots$ $\stackrel{s-5}{\mathrm{~B}} \mathrm{~F}_{3} \mathrm{OH}$ instead of $\stackrel{+}{\mathrm{C}}_{3} \mathrm{H}_{\overline{7}}$.

2) The attacking groupbeing a polarized complex, $\mathrm{C}_{3} \stackrel{i}{\mathrm{H}}_{7} \cdots \stackrel{\dot{b}}{\mathrm{~B}} \mathrm{~F}_{3} \mathrm{OH}$, the inductive effect of the alkyl group on the aromatic nucleus on it is not so influential as in the case of the attack by carbonium ions.

3) Hence, in this case, the steric or probability factor has the priority over the inductive effect in the propylation of aromatic hydrocarbons. This is the reason why benzene is the most reactive and has the strongest catalyst regenerating ability as compared with alkylbenzenes in the propylation reaction with $\mathrm{BF}_{3}-\mathrm{H}_{2} \mathrm{O}$ complex catalyst.

4) When the ester like complex, $\mathrm{C}_{3} \stackrel{8+}{\mathrm{H}_{7}} \cdots$ $\stackrel{\delta+}{\mathrm{B}} \mathrm{F}_{3} \mathrm{OH}$, approaches to an aromatic nucleus, the exchange of $\mathrm{C}_{3} \mathrm{H}_{7}$ in the complex for a proton on the aromatic nucleus occurs to produce alkylated aromatic hydrocarbons and regenerated catalyst $\mathrm{HBF}_{3} \mathrm{OH}$. And this exchange reaction can be accomplished only when the complex approaches very closely to the nucleus.

5) The attack of the ester like complex to the aromatic nucleus is accelerated by the presence of a large amount of the $\mathrm{BF}_{3}-\mathrm{H}_{2} \mathrm{O}$ complex catalyst of high $\mathrm{BF}_{3}$ concentration. Hence, the increase in the catalyst amount favors the elongation of the catalyst life.

6) In the polymerization of propylene with $\mathrm{BF}_{3}-\mathrm{H}_{2} \mathrm{O}$ complex catalyst, the deterioration of the catalyst (the accumulation of the ester like complex, $\left.\mathrm{C}_{3} \stackrel{\delta}{\mathrm{H}}_{7} \cdots \stackrel{8-}{\mathrm{B}} \mathrm{F}_{3} \mathrm{OH}\right)$ is more rapid than in the case of the propylation of benzene homologues. And the molar ratio of $\mathrm{C}_{3} \mathrm{H}_{6} / \mathrm{HBF}_{3} \mathrm{OH}$ in the ester like complex is found to be $1: 1$.

\section{Reference}

1) Yoneda, N., Aomura, K., Ohtsuka, H., Bull. Japan. Petrol. Inst., 8, 19 (1966).

2) Hasegawa, E., Yoneda, N., Aomura, K., Ohtsuka, H., 21th Annual Meeting of Japan Chem. Soc., Apr. 2 (1968).

3) Ohtsuka, H., Morita, T., Memoirs of Faculty of Enginecring Hokkaido Uniw., 10, 27 (1955).

4) I'oneda, N., Aomura, K., Ohtsuka, H., Bull. Japan. Petrol. Inst., 9, 26 (1967)

5) Olah, G. A., Flood S. H., Moffatt, M. E., J. Am. Chem. Soc., 86, 1046 (1964) 